\title{
Step Sisters of Cinderella
}

\author{
Santosh K. Chaturvedi ${ }^{1}$
}

Published online: 7 December 2015

(C) Springer India Pvt. Ltd. 2015

There can be much to learn from the fable of Cinderella, her wicked step sisters, step mother and the prince charming. It can be a story of many good people or disciplines which were neglected or rejected, out of sheer envy, jealousy, prejudice, or politics. The Cinderella syndrome affects many who are under appreciated despite being hard working and useful to the society. Psychiatric rehabilitation is one of such disciplines!

Psychiatric rehabilitation does not get its due importance in the field of mental health. Though all mental health professionals acknowledge its significance and key role somehow it does not get the significance it deserves. It is one field of mental health practice which is definitely under appreciated. This makes psychiatric rehabilitation as a Cinderella in the world of fairy tale of mental health practice. Much is written about many other specialties which are unique in their importance but neglected like Cinderella, little focus has been put on the specialties which get undue importance despite their relative low significance, like the step sisters of Cinderella. Let us examine these 'sister' specialties which get lop sided attention and advantages.

Many medical super- and sub-specialties in the fields of Cardiology, Pediatrics, Nephrology, Radiology and Neurology get a lot of attention from the public, health professionals and policy makers. In comparison to these specialties, psychiatry is a neglected one. The value of psychiatry is also under appreciated, especially in many developing countries. There is little time and amount of training in psychiatry undergraduate training programmes.

\footnotetext{
Santosh K. Chaturvedi

skchatur@gmail.com

1 Bangalore, India
}

There is short non serious clinical training during internship and little attention and importance in post graduate medical courses. The sister specialties which are popular and sought after mentioned above are important because of involvement of high technological advances in them. These also provide a scope of giving huge economic gains to health professionals and the equipment and pharmacological industries. These are also considered as specialties dealing with life threatening conditions and thus attracting urgent attention. In contrast, psychiatric disorders are sadly not considered as life threatening though there is high risk of death due to suicide, substance use, aggression and neglect. The medicines for specialties, other than psychiatry, are much more expensive than psychiatric medications. Graduates and postgraduates rush to these fields which drive them towards potentially luxurious and ornate specialties.

Within the field of psychiatry, for the same reasons given above, certain branches of psychiatry attract more attention, namely, biological psychiatry, neuroimaging, functional neuroimaging, genetics, molecular biology, genomics, proteomics, newer psycho pharmacological molecules and newer physical treatments. These newly appeared on the scene areas of studies dry up the investments and resources into the field of psychiatric researches, leaving fields such as rehabilitation vying for resources. The lack of resources for rehabilitation leads to lesser research in this field, making it further disheartening.

Psychosocial therapies, including psychosocial rehabilitation, get the back seat. These therapies are considered ineffective, slow in response, difficult to deliver and difficult to know the effectiveness. Research in neurobiological psychiatry is a wild goose chase, as the last half century of research as hardly paid any authentic results. The introduction of newer molecules of drugs has changed little in 
the outcome of the psychiatric disorders. Most drugs are equally effective with different side effects profiles. The newer exorbitantly expensive investigations have remained elusive and nonspecific in their findings, leading to further expensive searches for discovering the etiopathogenesis of psychiatric disorders.

One hopes that psychosocial rehabilitation will get its due importance in mental health practice so that at last the Cinderella finds its prince charming in the field of healthcare in general and mental health practice in particular. While the other fields should no doubt continue their endeavours, the desiderata of recovery oriented practices should not be forgotten.
The fourth issue of the journal has interesting viewpoints on disability, in relation to symptomatology, community interventions, relationship with other physical disabilities and quality of life. There are also two descriptions of Clubhouse Community Support and a "Well-being Program' for promotion of mental well-being for persons admitted to acute services". This rather slim issue paves way for measures to enhance research and essays on psychosocial rehabilitation, and compensate in the issues in the coming years. 